\title{
BIOMASS AND CARBON STOCK ESTIMATION USING IN-SITU OBSERVATIONS AND GIS IN GILGIT BALTISTAN, PAKISTAN
}

\author{
Eshrat Fatima ${ }^{a}$, Syeda Saleha Ali ${ }^{b}$

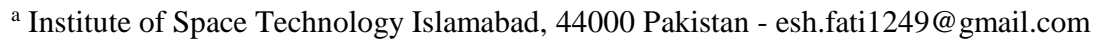 \\ b Institute of Space Technology Islamabad , 44000 Pakistan - saleha.ali1894@gmail.com
}

KEY WORDS: Aboveground Biomass, Carbon Sequestration, Remote Sensing, Landsat8, Vegetation Indices, Biomass Equations, REDD+

\begin{abstract}
:
Carbon dioxide (CO2) emission and other greenhouse gases are rising day by day due to anthropogenic activities which lead to global warming and cause natural disasters. Thus REDD+ comes up with an initiative to reduce emissions from deforestation through Carbon accounting, in which the under developing countries Measure, Report, and Verify (MRV) the sum of Above Ground Biomass (AGB)/carbon stored in a particular forest. Nonetheless, the major challenge for REDD+ is to find an accurate method for biomass estimation. The purpose of this study was to model and map the AGB and carbon stock of Gilgit-Baltistan, Pakistan. For this purpose, we linked Landsat 8 and forest inventory data to assess the potential of Vegetation Indices (Vis) derived AGB estimation. Inventory data consisted of the tree measurements from 480 plots that data was collected in the year (June-Oct) 2016 in a $72,971 \mathrm{~km}^{2}(28,174 \mathrm{sq} \mathrm{mi})$ study area, in Gilgit-Baltistan. Out of these plots, 287 was used in Calibration and 191 is used for Validation. This paper provides a regression equation between the reflection values from the Landsat- 8 satellite image and sample areas where terrestrial aboveground biomass (AGB) was calculated by direct measurement method. As a result of the calculations made, a positive linear correlation between AGB and NDVI was relatively high compared to other vegetation indices i.e 0.59 in the year 2016 or for the year 2013 .
\end{abstract}

\section{INTRODUCTION}

Carbon is one of the most essential elements of the earth. It exists in the form of carbon dioxide (CO2) gas in the earth's atmosphere. It has a very small concentration about $0.04 \%$ in the atmosphere but is chief among the greenhouse gases (GHG) with great influence on global climate patterns (Vashum \& Jayakumar, 2012). A report on climate change (IPCC, 2014) has declared that $\mathrm{CO} 2$ concentration in the atmosphere is increasing continuously by approximately $1.5 \mathrm{ppm}$ (parts per million) per year. It was estimated that $\mathrm{CO} 2$ concentration in the atmosphere has been reached up to $430 \mathrm{ppm}$ in 2011 from $280 \mathrm{ppm}$ in the pre-industrial era (1950) and through this trend of rising $\mathrm{CO} 2$ concentration, it has been predicted the earth's surface temperature may increase from $3.7^{\circ} \mathrm{C}$ to $4.8^{\circ} \mathrm{C}$ before next century (Sarker, 2010).

Forest dominates the dynamics of the global carbon cycle being the largest natural carbon pool of terrestrial ecosystems. (Kurz, Apps, Webb, \& McNamee, 1992). They act as the source of carbon emission and carbon sequestration simultaneously. Forest continuously exchanges $\mathrm{CO} 2$ with the atmosphere and is directly affected by natural processes and anthropogenic activities (S. Brown, 2002).

Around $31 \%$ of the total terrestrial area of the Earth is covered by forest; of some $22 \%$ is closed forest (able to store maximum Carbon). They intake $\mathrm{CO} 2$ from the atmosphere and water from the ground to produce carbohydrates (carbon-containing compounds) to make their biomass and release oxygen in the atmosphere through the photosynthesis process (Vashum \& Jayakumar, 2012). On average, around 50\% of the biomass can be assessed as the carbon content for all tree species (MacDicken, 1997).

Carbon sequestration is a natural and deliberate process of removing $\mathrm{CO} 2$ from the atmosphere and storing it in forest ecosystem in the form of soil's organic component and woody biomass of roots, trunks, foliage, and branches of the trees (K. Brown \& Pearce, 1994; McCarthy, 2001) while anthropogenic
Activities like deforestation, decomposition of plant's parts, burning of fossil fuels, and change in forest area leads towards the $\mathrm{CO} 2$ emission.

Biomass can be considered as the quantity of alive matter stored in a habitat (Kindermann, Mccallum, Fritz, \& Obersteiner, 2008), stated either as the number of organisms per unit volume or area of habitat, produced by the photosynthesis process with the energy input from the sun and $\mathrm{CO} 2$ from the atmosphere. The study of biomass is significant as it is a major carbon cycle component and assists in determining the climate change and global warming phenomenon. Total Aboveground Biomass (AGB) assessment in a forest, termed as biomass density, is a very useful way to estimate the amount of resource available.

The majority of studies on the biomass assessment have focused on AGB as it stores a vast amount of total accumulated biomass in the forest ecosystem whereas the belowground biomass is rarely measured because it requires labor-intensive and timeconsuming in-situ measurements. As carbon makes up approximately $50 \%$ of vegetative biomass, quantification of the biomass is important in forest ecosystem studies to estimate carbon pools at multiple scales (Ghasemi et al., 2011).

In the last few years, remote sensing methods have become prevalent for spatially explicit quantification of forest biophysical parameters in terms of AGB or growing stock volume. These methods are closely associated with the quantity of carbon available in forest components and enabled to monitor biomass on a regional and even on a global scale realistic and cost-effective way (Hamdan, Aziz, \& Rahman, 2011; Malhi et al., 2002; Yavasli, 2013; Zheng et al., 2004).

Although, AGB cannot be assessed directly through any remote sensing instruments. We required field measurements of allometric functions for the implementation and evaluation of AGB estimation models (Chave et al., 2005; Goetz et al., 2009; Hamdan et al., 2011). The radiometry is sensitive to forest stand structure (tree density and crown size) and texture, and correlation is drawn between in-situ field measurements and spectral responses derived from multi-spectral remote sensing 
data using a chosen method (Ghasemi et al., 2011; Yavasli, 2013).

Despite various proposals to stop deforestation, the world continues to drop forests every year. This alarming situation has led researchers to conduct studies on the decline of forest reserves all over the world. Various researches verify the potential of integrating high-resolution remote sensing digital data and aerial photography for understanding changes in land cover patterns.

Climate change is happing worldwide due to anthropogenic activities which affect several environmental, social, and economic aspects of life. Greenhouse gases level is rising and is now at their highest atmospheric concentrations. Thus UNFCC under the REDD+ program recommended a monitoring system that combines remote sensing and ground-based inventories for estimating forest biomass and carbon stock (IPCC, 2014; Malhi et al., 2002).

The major challenge for REDD+ is to come up with an accurate method to measure and estimate the forest biomass most specifically in tropical forests. Several studies have been done using medium resolution optical satellite images to estimate AGB.

These studies derive Indices (Vis) such as Normalized Difference Vegetation Index (NDVI), Enhanced vegetation Indices (EVI), and the Simple ratio (SR) from optical images of Landsat-TM to estimate AGB since the indices correlate with AGB estimated from the field data.

The study of biomass is significant as it is a major carbon cycle component and assists in determining the climate change and global warming phenomenon. The Total AGB assessment of a forest, termed as biomass density, is a very useful way for estimation the number of resources available. The estimation of forest AGB is a challenging job, particularly in areas with complex forest stand structures and environmental conditions, and requires precise and consistent estimation methods ( $\mathrm{Lu}$, 2006). To date, no universally applicable method has been developed for the estimation of biomass, although many attempts have been made during the last few decades.

In Remote Sensing based biomass assessment, biomass equation is still important to estimate plot biomass which is correlated with spectral data for large-scale mapping. Models derived from $\mathrm{RS}$ and verified with ground data can be used appropriately to predict AGB for a given landscape.

The study aims to estimate the AGB by integrating Landsat 8 derived VI in the Gilgit-Baltistan forest. Thus, moving a step forward in assisting the REDD+ initiative to achieve its goals towards sustainable forest management. The objectives include the above-ground biomass estimation by integrating Vegetation indices (VIs) i.e NDVI, TNDVI, GNDVI, SAVI, TSAVI, MSAVI2, to assess biomass and carbon stock estimates per unit area (ha) using field data, to map AGB and carbon stock of Gilgit-Baltistan forest, estimation and validation of AGB for selected sites using regression models, to compare the Linear and Exponential relationship between the Vis and AGB.

\section{STUDY AREA}

The Gilgit-Baltistan of Pakistan stretches from $35^{\circ}-37^{\prime} \mathrm{N}$ (latitude) to $72^{\circ}-75^{\prime} \mathrm{E}$ (longitude). Having an almost 1.8 million population (GBWFE, 2013) and is spread over an area of 72, 496 sq. km, bordering China, Afghanistan, and India. This region has been divided into seven districts; Gilgit, Diamer, Skardu, Ghanche, Ghizer, Astore, and Hunza-Nagar. Each of these districts has been sub-divided into subdivisions. The area has a multifaceted topography ranging from mountain ranges and water sinks, source lakes and riverine, the world`s largest glaciers, and indeed, forests. Forest cover in Gilgit-Baltistan is roughly estimated at four percent while about five percent of the land is covered in forest plantations. It is this wood that the mafia is after. The mountainous region consisting of more than 108 peaks, of which fifty peaks are above 7000 meters above sea level, and none of the peaks are less than 4000 meters. GB has a varying climate depending on the locations of the region. The climate in the western Himalayan zone is moist, whereas the Karakoram and Hindu Kush zones possess a dry climate. It is recorded that Gilgit and Chilas are very hot in summer during the daytime, but cold at night. The areas like Astore, Khaplu, Yasin, Hunza, and Nagar are cold all year round.

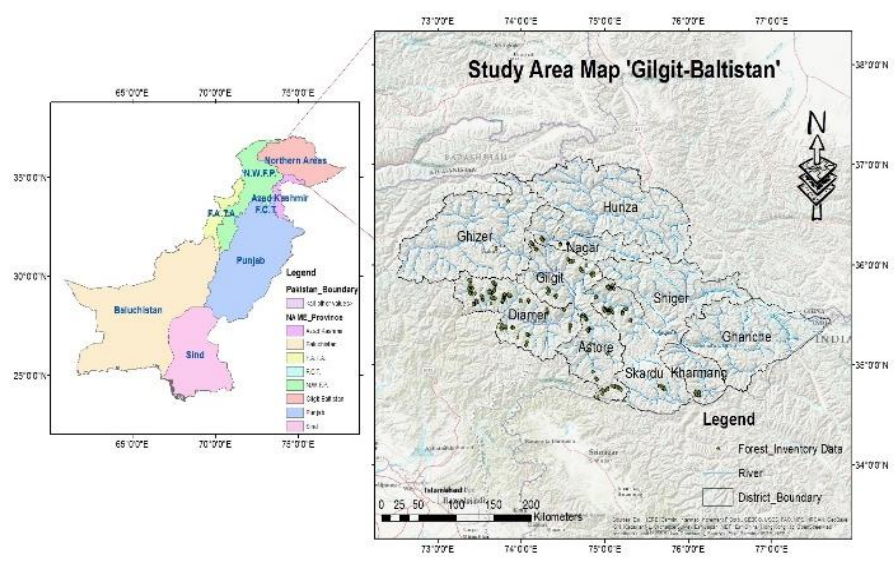

Figure 1. Study Area Map.

\begin{tabular}{|c|c|}
\hline Variable & Attributes \\
\hline Latitude & $35^{\circ}-37^{\prime} \mathrm{N}$ \\
\hline Longitude & $72^{\circ}-75^{\prime} \mathrm{E}$ \\
\hline Total Area covered & 72, 496 sq. Km Approx \\
\hline Natural Forest Covered & roughly $4 \%$ \\
\hline $\begin{array}{l}\text { land covered in forest plantations (e.g., } \\
\text { planted fruit trees, poplars, etc }\end{array}$ & roughly $5.36 \%$ \\
\hline $\begin{array}{l}\text { Total No of Tree species identified } \\
\text { during the filed campaigns }\end{array}$ & $\begin{array}{ll}\text { Nine } & \\
\text { - } & \text { Abies pindrow } \\
\text { - } & \text { Pedrus deodara } \\
\text { - } & \text { Picea smithiana } \\
\text { - } & \text { Pinus wallichiana } \\
\text { - } & \text { Pinus gerardiana } \\
\text { - } & \text { Quercus ilex } \\
\text { - } & \text { Betula utilis } \\
\text { - } & \text { Juniperous communis } \\
\text { - } & \text { Taxus baccata }\end{array}$ \\
\hline
\end{tabular}

Table 1. Major Physical Characteristics of the Gilgit-Baltistan.

\section{MATERIAL AND METHODS}

\subsection{Datasets}

Materials including software, satellite image datasets, and field observations are an important part of any research. Therefore, 
this section introduces the list of materials used to conduct this research.

\subsubsection{Satellite Image acquisition}

The Landsat8 OLI/TIRS C1 Level-1 satellite images which are composed of $30 * 30 \mathrm{~km}^{2}$ tile (Ortho-images with UTM/WGS84 projection), were acquired from the earthexplorer.usgs.gov website. The acquisition date of the images are as follow.

Images consist of nine spectral bands with a spatial resolution of 30 meters for Bands 1 to 7 and 9. The ultra-blue Band 1 is useful for coastal and aerosol studies. Band 9 is useful for cirrus cloud detection. The resolution for Band 8 (panchromatic) is 15 meters. Thermal bands 10 and 11 are useful in providing more accurate surface temperatures and are collected at 100 meters. The approximate scene size is $170 \mathrm{~km}$ north-south by $183 \mathrm{~km}$ east-west (106 mi by $114 \mathrm{mi})$.

\begin{tabular}{|c|l|l|l|}
\hline $\begin{array}{c}\text { Landsat8 } \\
\text { imagery }\end{array}$ & Row/path & $\begin{array}{c}\text { Land Cloud } \\
\text { Cover }\end{array}$ & Date of acquisition \\
\hline \multirow{4}{*}{$\begin{array}{c}\text { Landsat } \\
\text { OLI }\end{array}$} & $148-36$ & 4.6 & 16-Mar-2016 \\
\cline { 2 - 4 } & $150-34$ & 2.51 & 20-Jul-2016 \\
\cline { 2 - 4 } & $150-35$ & 5.70 & 20-Jul-2016 \\
\cline { 2 - 4 } & $150-36$ & 3.29 & 20-Jul-2016 \\
\cline { 2 - 4 } & $151-35$ & 7.45 & $28-$ Sep-2016 \\
\cline { 2 - 4 } & $148-35$ & 6.17 & 24-Sep-2016 \\
\cline { 2 - 4 } & $149-34$ & 3.09 & 01-Oct-2016 \\
\cline { 2 - 4 } & $149-35$ & 1.87 & $01-$ Oct-2016 \\
\cline { 2 - 4 } & $149-36$ & 1.22 & $01-$ Oct-2016 \\
\hline
\end{tabular}

Table 2. Landsat 8 Operational Land Imager (OLI) and Thermal Infrared Sensor (TIRS) Launched 2016.

\subsubsection{Image Processing}

The data analysis process was carried out in different phases, depending on the type which included Landsat- 8 satellite images. The processing was done using various software such as ArcGIS and ENVI.

\subsubsection{Pre-processing/radiometric correction}

Radiometric correction of Landsat- 8 optical images was done to improve the quality of the image by using ENVI software. The main purpose of radiometric correction was to reduce the atmospheric and sun angle effects (Baillarin et al., 2012). The images were transformed from radiance to surface reflectance, by applying the Dark Object Subtraction (DOS) method using the ArcGIS software. The DOS method works by removing the darkest pixel in each band that might affect by atmospheric scattering (Chave, 1988). The images were mosaicked and the study area was extracted afterward.

\subsubsection{Software and tools}

Apart from the satellite datasets and the software used, field equipment was also considered important for conducting this research.

\begin{tabular}{|l|l|}
\hline Software & Purpose \\
\hline ENVI 5.1 & Image processing \\
\hline ArcMap 10.3 & $\begin{array}{l}\text { Extracting Vegetation indices } \\
\text { pixel value }\end{array}$ \\
\hline
\end{tabular}

\begin{tabular}{|l|l|}
\hline Microsoft office word & Project report writing \\
\hline Microsoft office excel & Statistical analysis \\
\hline
\end{tabular}

Table 3. Software and tools for processing and analysis.

\subsection{Methodology}

The methodology, which has been adopted for the analysis of field measurements, pre-processing of Landsat- 8 images, and details about the models developed for retrieval and assessment of AGB for the study sites can be found below.

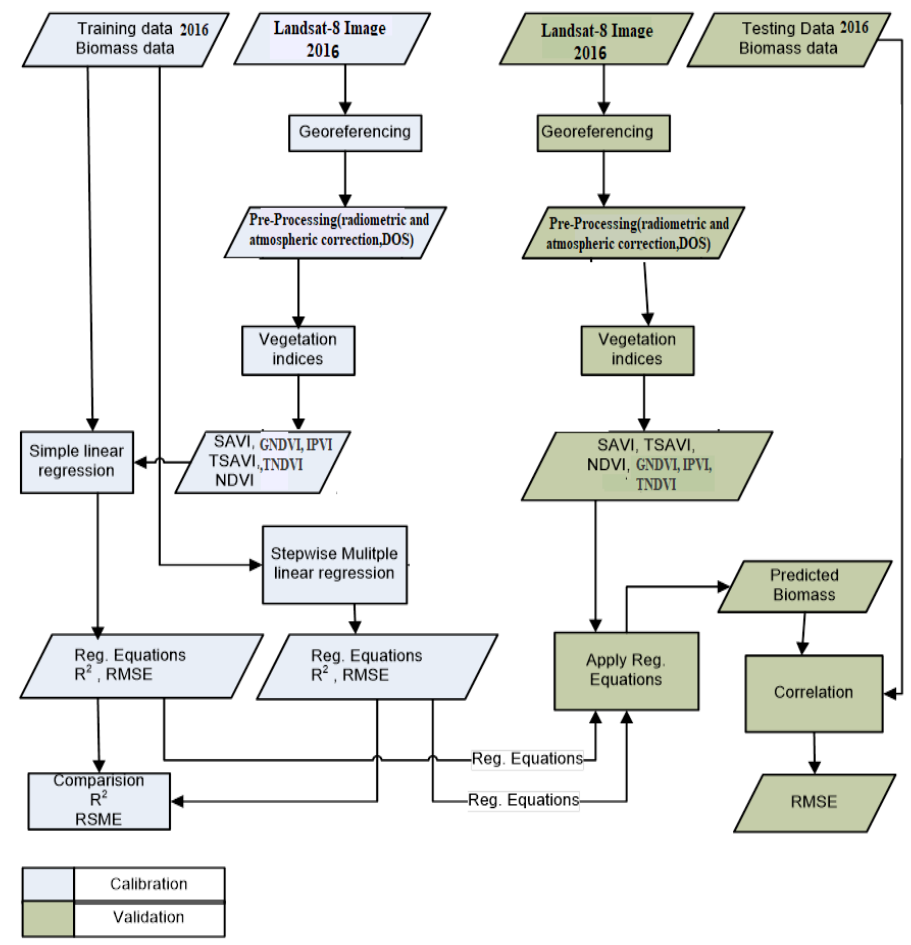

Figure 2. Working Methodology.

3.2.1 Symbols and Units: Use the SI (System International) Units and Symbols. Unusual characters or symbols should be explained in a list of nomenclature.

\subsection{Deriving Vegetation Indices (VIs) from Landsat Optical satellite image}

The indices were computed using Landsat- 8 image spectral bands through SNAP software. The selection of the indices was based on its performance in biomass estimation in previous studies. There are over 150 vegetation indices but for this study, only 6 indices were selected.

\subsubsection{Broadband VIs}

Vis is sensitive to the canopy leaf area. The indices are used for monitoring of the vegetation since they use the near-infrared (NIR) spectral band which has a high reflectance of vegetation and the red spectral band which has high absorption by vegetation. For this study the following broadband indices were used.

\subsubsection{Normalized Difference vegetation index (NDVI)}


NDVI is one of the most widely used VI for biomass estimation (Rouse et.at., 1974).

$$
N D V I=\frac{(N I R-R E D)}{(N I R+R E D)}
$$

\subsubsection{Soil-adjusted Vegetation Index (SAVI)}

The SAVI is structured similar to the NDVI but with the addition of a "soil brightness correction factor".

Where NIR is the reflectance value of the near-infrared band, RED is the reflectance of the red band, and $\mathrm{L}$ is the soil brightness correction factor. The value of $\mathrm{L}$ varies by the green vegetation cover in very high vegetation regions, $\mathrm{L}=0$; and in areas with no green vegetation, $\mathrm{L}=1$. Generally, an $\mathrm{L}=0.5$ works well in most situations and is the default value used. When $\mathrm{L}=0$, then SAVI $=$ NDVI.

$$
S A V I=\frac{1.5 *(N I R-R E D)}{(N I R+R E D+0.5)}
$$

3.3.4 Transformed Soil Adjusted Vegetation Index (TSAVI)

$$
T S A V I=\frac{\{a(N I R-a R E D-b)\}}{R E D+a N I R-a b}
$$

\subsubsection{Transformed NDVI}

To avoid dealing with negative values derived from NDVI, a constant of 0.5 was added, and to approximate the normal distribution, a square root was introduced.

$$
T N D V I=\sqrt{N D V I+0.5}
$$

\subsubsection{Green Normalized Difference Vegetation Index (GNDVI)}

This index is similar to NDVI except that it measures the green spectrum from 540 to $570 \mathrm{~nm}$ instead of the red spectrum. This index is more sensitive to chlorophyll concentration than NDVI.

$$
G N D V I=\frac{(N I R-G R E E N)}{(N I R+G R E E N)}
$$

\subsection{Coefficient of determination $\left(\mathbf{R}^{2}\right)$}

The observed and modelled results are compared and their correlation is evaluated to know how well the model works by using the following equation.

$R^{2}=\left\{\frac{\sum_{i=1}^{n}\left(Q_{o b s i}-Q_{o b}\right)\left(Q_{o b s i}-Q_{o b}\right)}{\left[\sum_{i=1}^{n}\left(Q_{o b s i}-Q_{o b}\right)^{2}\right]^{0.5}\left[\sum_{i=1}^{n}\left(Q_{s i m i}-Q_{s i m}\right)^{2}\right]^{0.5}}\right\}^{2}$

The $\mathrm{R}^{2}$ ranges from zero to one, with higher $\mathrm{R}^{2}$ values representing better model performance.

\section{RESULTS AND DISCUSSION}

This Section describes the results and outcomes in terms of AGB estimation models and AGB spatial distribution in terms of maps of study areas, which have been developed by applying the designed methodology.

\subsection{Calculation of Vegetation Indices (VIs)}

The calculation of the VIs was done using SNAP software. All six indices were computed using the formula stated in the methodology. The sic VIs resulted images which can be as seen in Figure below.
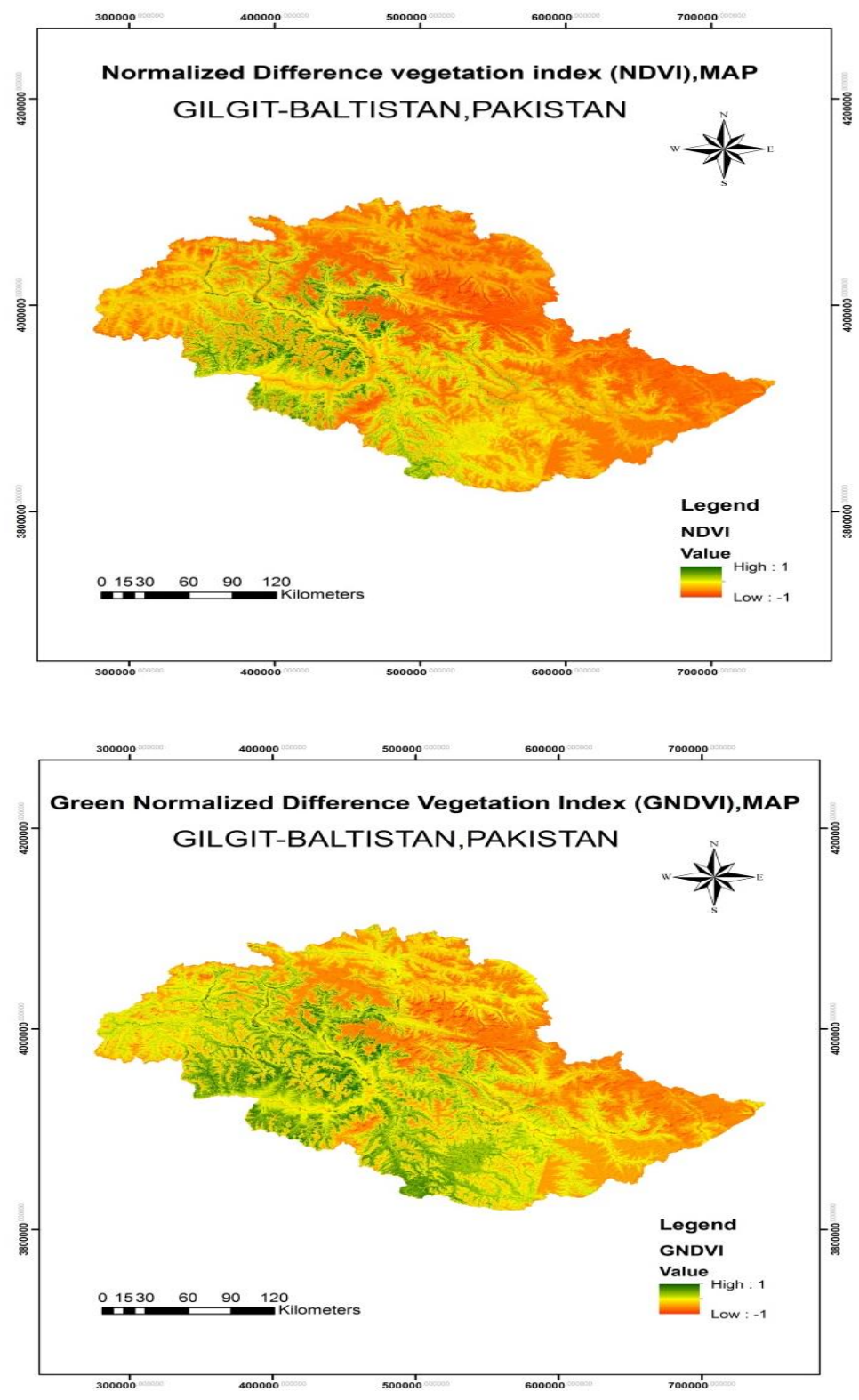

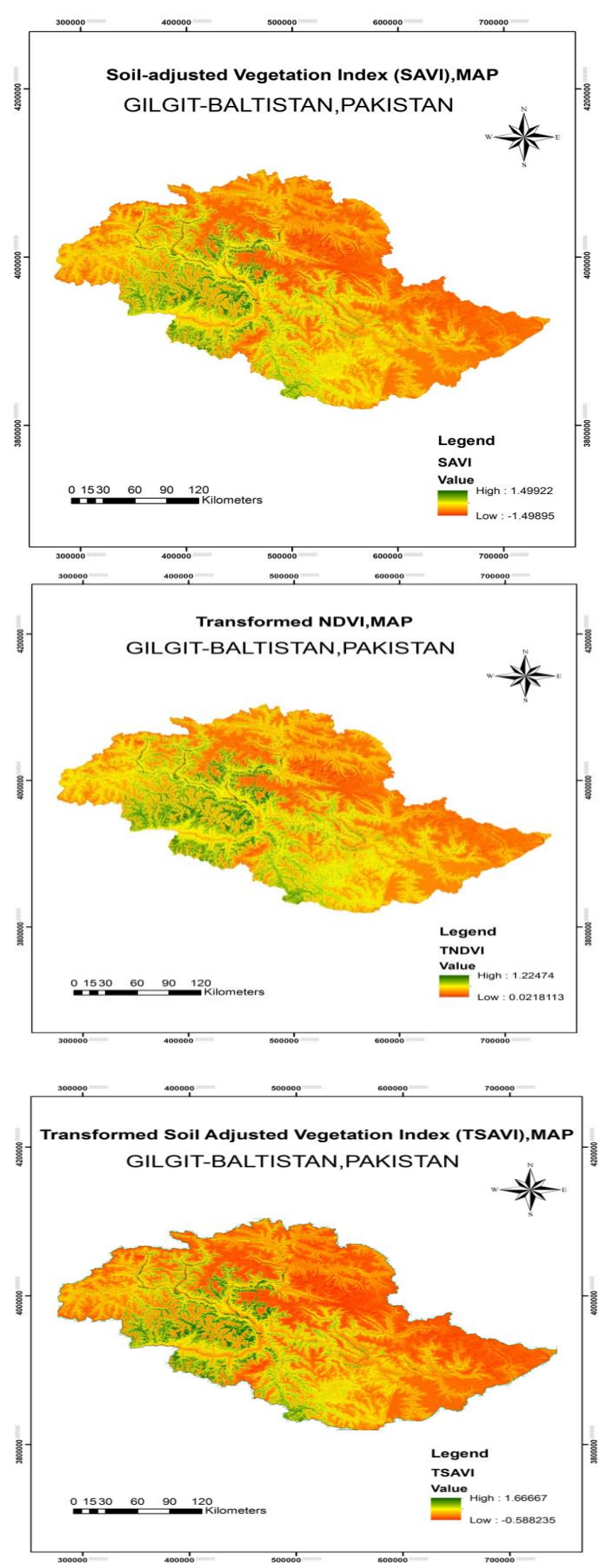

Figure 3. Calculation of Vegetation Indices (VIs) 2016.

\subsection{Statistical analysis}

The correlation observed between indices and biomass indicate that infrared images allow need a better determination of crop biomass in the study area, more information on the characteristics is given below in the Table

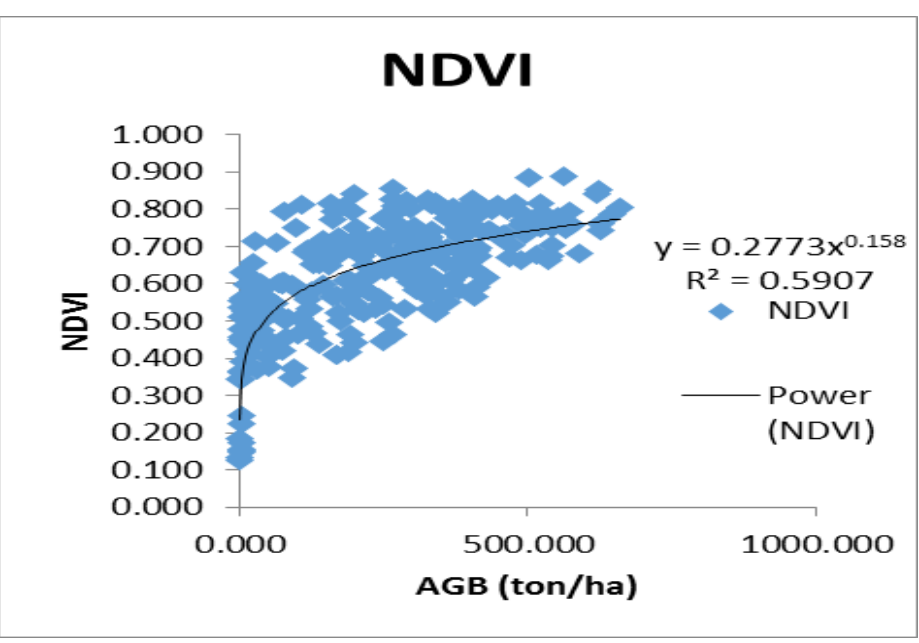

Figure 4.

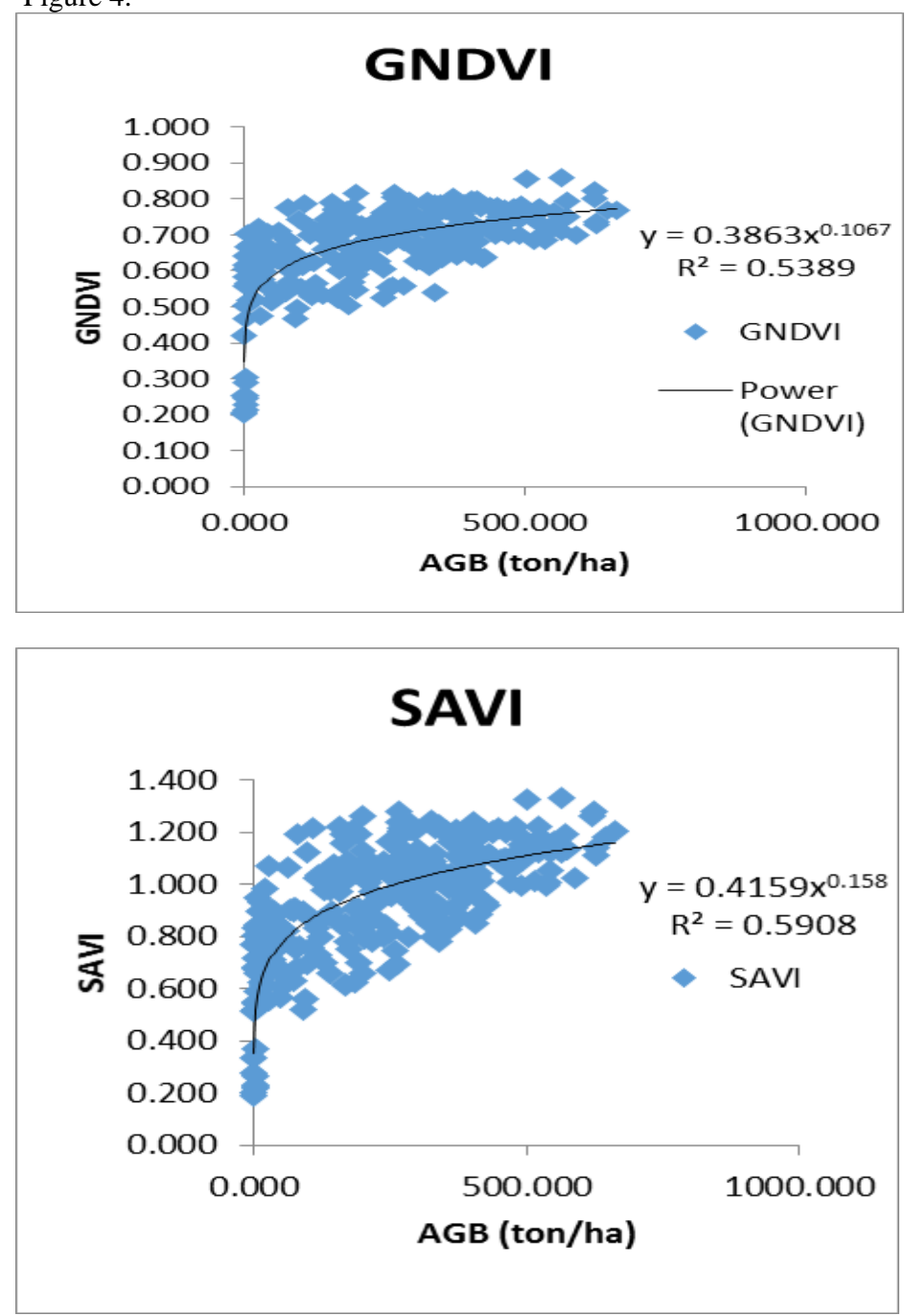



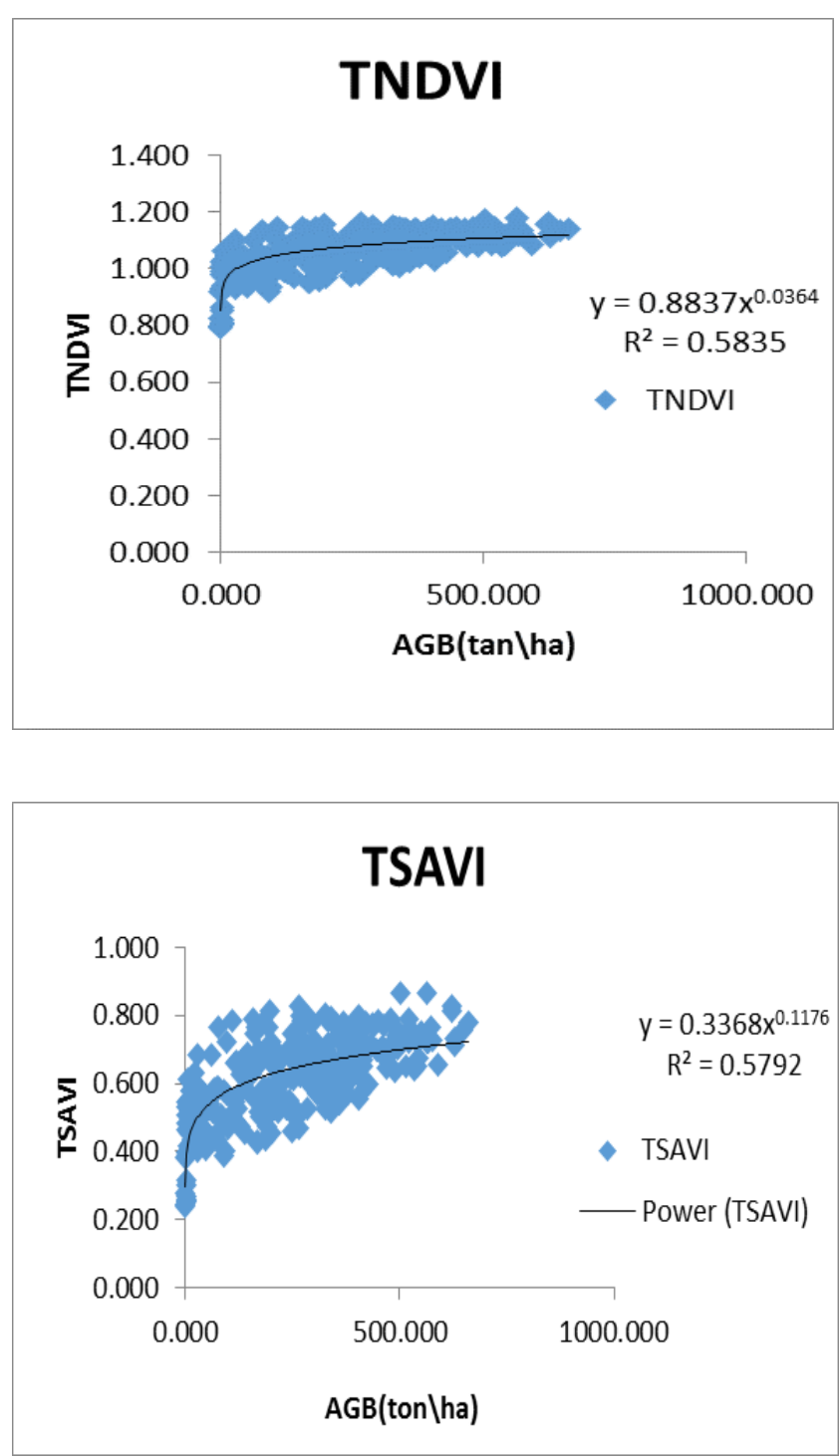

Figure 4. Statistical Analysis between VIs and Observed Biomass

\begin{tabular}{|c|c|c|c|}
\hline Index & Equation & $\mathrm{R}^{2}$ & Author \\
\hline NDVI & $N D V I=(N I R-R E D)$ & 0.59 & Rouse et \\
\hline GNDVI & $G N D V I=\frac{(N I R-G R E E N)}{(N I R+G R E E N)}$ & 0.53 & $\begin{array}{l}\text { Gitelsonet } \\
\text { al., (1996) }\end{array}$ \\
\hline SAVI & $S A V I=\frac{1.5 *(N I R-R E D)}{}$ & 0.59 & Huete \\
\hline TSAVI & $\begin{array}{c}(N I R+R E D+0.5) \\
\text { TSAVI }=\frac{\{a(N I R-a R E D-b)\}}{}\end{array}$ & 0.58 & $\begin{array}{l}\text { Baret et } \\
\text { al. (1989) }\end{array}$ \\
\hline TNDVI & $T N D V I=\frac{R E D+a N I R-a b}{\sqrt{N D V I+0.5}}$ & 0.57 & $\begin{array}{l}\text { Tucker } \\
(1979)\end{array}$ \\
\hline
\end{tabular}

Table 4. Comparison between Biomass Estimation Methods.

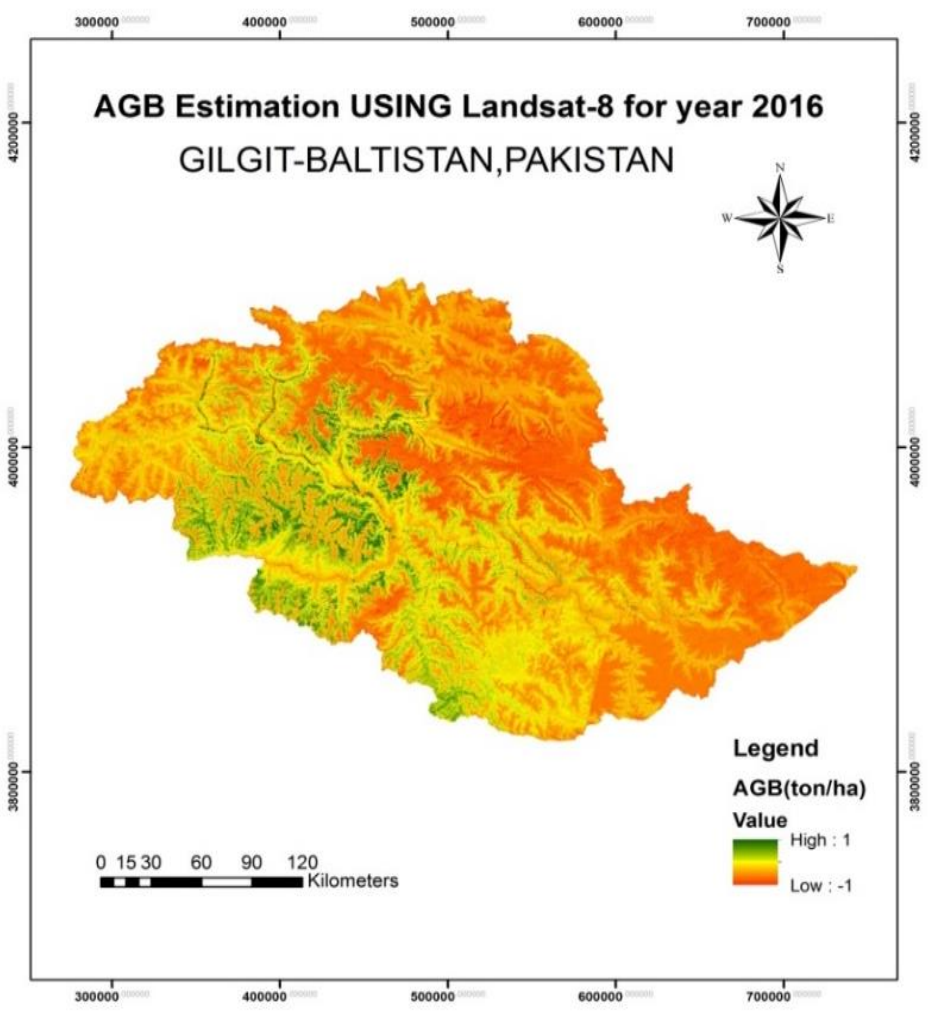

Figure 5. Carbon StockLandsat-8 of Gilgit-Baltistan of year 2016

The remote sensing data by using the single index or combining different spectral indices of optical satellite imagery for AGB estimation can in the future be utilized for reliable estimation and assessment of the changes in biomass.

The study demonstrated encouraging results in forest AGB mapping of the normal vegetated area using Landsat imagery; thus, it is helpful and valuable for vital information mining from the Landsat series when it is applied to global forest AGB estimation.

The maps generated will be instrumental for formulating spatially-targeted climate change mitigation and sustainable land management strategies.

In the future, the performance will be improved by incorporating other important environmental data (e.g., distance to the city center and roads, as well as human disturbance) and other up-to-date remote sensing techniques (e.g., Tandem-X and LiDAR), as well as the stochastic component of AGB.

The study will be helpful for "sustainable forest management" and preserve biomass.

Due to the cloud cover we were not able to use the Sentinel or high resolution imagery from March to october.

Due to the large scale mapping and the complex terrain area the correlation of AGB from indices with the field In-Situ observed data due to which the results seems not so strong.

\section{ACKNOWLEDGEMENTS}

This work was performed under the Forest Carbon Partnership Facility (FCPF) -World Bank REDD+ Readiness (R-PP) Project, Ministry of Climate Change, Government of Pakistan to reach REDD+ (Reduction of Emissions from deforestation and forest degradation) readiness this was Three Months Research internship done in Geospatial Research and Education Lab (GREL) at Department of Space Science, Institute of Space Technology (IST) Islamabad. 
The core field data was collected by the Department of Forest and Wildlife, Gilgit-Baltistan, Pakistan.

We gratefully acknowledge contributions from the (FCPF) World Bank REDD+ Readiness (R-PP) Project and GilgitBaltistan forest department.

\section{REFERENCES}

Vashum KT, Jayakumar S. Methods to estimate above-ground biomass and carbon stock in natural forests-a review. J. Ecosyst. Ecogr. 2012;2(4):1-7.

Kurz WA, Apps MJ, Webb TM, McNamee PJ. The Carbon Budget of the Canadian Forest Sector: Phase I. Forestry Canada, Northwest Region, Northern Forestry Centre. Information report NOR-X-326. 1992.

Team CW, Pachauri RK, Meyer LA. IPCC, 2014: climate change 2014: synthesis report. Contribution of Working Groups I. II and III to the Fifth Assessment Report of the intergovernmental panel on Climate Change. IPCC, Geneva, Switzerland. 2014;151.

Malhi Y, Meir P, Brown S. Forests, carbon and global climate. Philosophical Transactions of the Royal Society of London A: Mathematical, Physical and Engineering Sciences. 2002 Aug 15;360(1797):1567-91.

MacDicken KG. A guide to monitoring carbon storage in forestry and agroforestry projects.

McCarthy JJ, editor. Climate change 2001: impacts, adaptation, and vulnerability: contribution of Working Group II to the third assessment report of the Intergovernmental Panel on Climate Change. Cambridge University Press; 2001 Jul 2.

Malhi Y, Meir P, Brown S. Forests, carbon and global climate. Philosophical Transactions of the Royal Society of London A: Mathematical, Physical and Engineering Sciences. 2002 Aug 15;360(1797):1567-91.

Kindermann G, McCallum I, Fritz S, Obersteiner M. A global forest growing stock, biomass and carbon map based on FAO statistics. Silva Fennica. 2008;42(3):387-96.

Ghasemi K, Ghasemi Y, Ehteshamnia A, Nabavi SM, Nabavi SF, Ebrahimzadeh MA, Pourmorad F. Influence of environmental factors on antioxidant activity, phenol and flavonoids contents of walnut (Juglans regia L.) green husks. Journal of Medicinal Plants Research. 2011 Apr 4;5(7):112833.

Hamdan O, Aziz HK, Rahman KA. Remotely sensed L-Band SAR data for tropical forest biomass estimation. Journal of Tropical Forest Science. 2011 Jul 1:318-27.

Ponce-Hernandez R, Koohafkan P, Antoine J. Assessing carbon stocks and modelling win-win scenarios of carbon sequestration through land-use changes. Food \& Agriculture Org.; 2004.

FAO. (2010). Global Forest Resources Assessment 2010. FAO Forestry Paper 163. FAO FORESTRY PAPER. http://doi.org/ISBN 978-92-5-106654-6
FAO. (2010). Global Forest Resources Assessment 2010. Progress Towards Sustainable Forest Management. Forestry Paper (Vol. 147). http://doi.org/ISBN 978-92-5-106654-6

Ghasemi, N., Sahebi, M. R., \& Mohammadzadeh, A. (2011). A Review on Biomass Estimation Methods Using Synthetic Aperture Radar Data. International Journal of Geomatics and Geosciences, 1(4), 776-788

IPCC. (2014). Climate Change 2014: Mitigation of Climate Change. Retrieved from http://report.mitigation2014.org/spm/ipcc_wg3_ar5_summaryforpolicymakers_pproved.pdf

Lu, D. (2005). Aboveground Biomass Estimation Using Landsat TM Data in the Brazilian Amazon. International Journal of Remote Sensing, 26(12), 2509-2525. http://doi.org/10.1080/01431160500142145

Lu, D. (2006). The Potential and Challenge of Remote Sensing Based Biomass Estimation. International Journal of Remote Sensing, 27(7), 1297-1328. http://doi.org/10.1080/01431160500486732

Mette, T. (2006). Forest Biomass Estimation from Polarimetric SAR Interferometry.MacDicken, K. G. (1997). A Guide to Monitoring Carbon Storage in Forestry and Agroforestry Projects. Winrock International Institute for Agricultural Development.

McCarthy, J. J. (2001). Climate Change 2001: Impacts, Adaptation, and Vulnerability: Contribution of Working Group II to the Third Assessment Report of the Intergovernmental Panel on Climate Change. Cambridge University Press.

Malhi, Y., Meir, P., \& Brown, S. (2002). Forests, Carbon and Global Climate. Phil. Trans. R. Soc. Lond. A, 360(1797), 15671591. http://doi.org/10.1098/rsta.2002.1020

Metz, B., \& Davidson, O. (2007). Climate Change 2007. Ravindranath, N. H., \& Ostwald, M. (2007). Carbon Inventory Methods: Handbook for Greenhouse Gas Inventory, Carbon Mitigation and Roundwood Production Projects. Springer Science 